\title{
PAULO FREIRE CENTENÁRIO COM UMA OBRA CINQUENTENÁRIA
}

DOI: 10.48075/ri.v23i1.26699

José Eustáquio Romão

Natatcha Priscilla Romão ${ }^{2}$

RESUMO: Este artigo lembra que a melhor maneira de homenagear um pensador é demonstrando a atualidade de sua obra. Pedagogia do oprimido, a obra mais conhecida de Paulo Freire, completou 50 anos de sua primeira edição em 2020. No centenário de nascimento de Paulo Freire, em 19 de setembro de 2021, ela completa 51 anos e continua liderando, de todas as obras de pensadores brasileiros sua disseminação pelo mundo, em centenas de traduções e edições e em milhões de exemplares vendidos, numa demonstração de sua importância no século XXI. O artigo reconstitui, historicamente, a elaboração dos originais e a trajetória das edições, com destaque para as primeiras, mormente para a realizada no Brasil, por causa de sua proibição imposta pela ditadura militar que se instalara no país em abril de 1964 e que banira Paulo Freire, bem como seu pensamento como "subversivo" da ordem autocrática imposta. Hoje, a onda neoconservadora que percorre parte da sociedade brasileira tenta, sem sucesso, exilá-lo de novo, mesmo que postumamente, bem como banir seu pensamento.

Palavras-chave: Edição; Exílio; Manuscrito; Oprimido; Pedagogia.

\section{PAULO FREIRECENTENARY WITH A CINQUENTENARY WORK}

ABSTRACT: This article recalls that the best way to honor a thinker is to demonstrate the timeliness of his work. Pedagogy of the oppressed, Paulo Freire's best-known work, completed 50 years of its first edition in 2020. In the centenary of Paulo Freire's birth, on September the 19th, 2021, it turns 51 and continues to lead, of all the works of Brazilian thinkers spread throughout the world, in hundreds of translations and editions and in millions of copies sold, in a demonstration of its importance in the 21st century. The article historically reconstitutes the elaboration of the originals and the trajectory of the editions, with emphasis on the first ones, especially the one carried out in Brazil, because of its prohibition imposed by the military dictatorship that had settled in the country in April 1964 and which Paulo Freire, as well as his thought as "subversive" of the imposed autocratic order. The neoconservative wave that runs through today part of Brazilian society tries, without success, to exile him again, even if posthumously, as well as to banish his thought.

Keywords: Editing; Exile; Manuscript; Oppressed; Pedagogy.

\footnotetext{
${ }^{1}$ Doutor em Educação. Diretor e Professor do Programa de Pós-Graduação em Educação da Universidade Nove de Julho (PPGE-Uninove). E-mail: jer@terra.com.br - ORCID: http://orcid.org/0000-0001-9276-0039 - Brasil. ${ }^{2}$ Graduada em Psicologia pelo Centro de Ensino Superior de Juiz de Fora, MG; Mestre em Psicologia, pela Universidade Federal de Juiz de Fora, MG e Doutora, pelo Programa de Pós-graduação da Universidade Nove de Julho de São Paulo. E-mail: natatcha.priscilla@gmail.com - ORCID: http://orcid.org/0000-0002-4803-4977 Brasil.
} 


\section{INTRODUÇÃO}

As comemorações dos 50 anos da conclusão do manuscrito de Pedagogia do oprimido por Paulo Freire, em Santiago do Chile, na primavera de 1968, foram realizadas em várias partes do mundo no ano de 2018. Em 2020, comemoram-se os 50 anos da primeira edição da obra que, ao que tudo leva a crer, teria sido em espanhol, no Uruguai, no ano de 1970, poucos meses antes de sua primeira edição em inglês, nos Estados Unidos. Em 2021, comemora-se o centenário de nascimento de Paulo Freire, em 19 de setembro de 1921. Nesse contexto festivo, cabe revelar a atualidade do livro, além de se dever evidenciar, por um lado, circunstâncias curiosas de sua redação original e, por outro lado, astúcias ideológicas e de segurança nas suas primeiras edições no Brasil e no mundo.

Em relação à redação do texto, permanecem as dúvidas sobre o fato de Paulo Freire ter produzido um manuscrito completo da obra, de que teriam sido sacadas fotocópias; ou se, com base em uma versão datilografada, ele teria passado o livro a limpo, à mão, gerando um manuscrito a posteriori, com qual presenteou o ex-ministro da Agricultura do Presidente Salvador Allende, Jacques Chonchol e sua esposa, Maria Edy, uma brasileira de Americana que o chileno conhecera nas festividades do quarto centenário da cidade de São Paulo.

No que diz respeito às primeiras edições, certamente houve editores que, tentando ludibriar a censura prévia dos países que viviam sob regimes ditatoriais na América Latina, omitiram trechos que poderiam comprometer a publicação, como foi o caso do Brasil, que amargava o "endurecimento" da ditadura militar. Neste caso, além de banido do País, Paulo Freire tinha sua produção intelectual proibida nas fronteiras nacionais. Em decorrência, a mutilação da obra, especialmente do desenho que Paulo fez sobre a "teoria da ação revolucionária" comparando-a com a "teoria da ação opressora" (cf. FREIRE, 2018, p. 322 e $323^{3}$ ) para viabilizar a publicação, se deu com o conhecimento e a anuência do autor, como parece ter sido o caso das primeiras edições de Pedagogia do oprimido pela Editora Paz e Terra no Brasil. Evidentemente, não se justifica a obra continuar sendo publicada da mesma forma depois da redemocratização do País, a partir de 1985, mantendo as mutilações nas mais de 70 edições.

\footnotetext{
${ }^{3}$ As citações de Pedagogia do oprimido serão extraídas da edição em fac-simile do manuscrito (2018). 
Em outros casos, as omissões, alterações, emendas e acréscimos tanto podem ter se dado por razões de tradução ${ }^{4}$, quanto podem ter sido resultado de tentativas de esconder o caráter revolucionário do livro, ou como muito bem se expressou Peter McLaren no lançamento de Che Guevara, Paulo Freire y la pedagogía de la revolución (2001), na Feira de Guadalajara: "Este título de meu livro não é uma jogada editorial. Ele tem a intenção de tornar a obra escrita de Che mais conhecida nos Estados Unidos e a de 'desdomesticar' Paulo Freire que já é tão conhecido do público norte-americano". Em suma, o que o educador norteamericano quis dizer é que, lamentavelmente, embora muito divulgado nos Estados Unidos, Paulo Freire fora (e é) relativamente "domesticado" e esta "domesticação deve ter se iniciado na tradução (adaptação) e publicação de sua obra mais importante naquele país.

Felizmente, os manuscritos originais foram encontrados e sua divulgação vem resgatando o caráter revolucionário da obra maior de Paulo Freire, além de permitir, aos editores, a publicação das próximas edições de acordo com os originais mais autênticos, permitindo, à humanidade, o acesso à verdadeira obra que se destaca como uma das mais importantes produzidas no século XX.

Em 2018, vários e expressivos foram os eventos comemorativos do cinquentenário da conclusão da redação de Pedagogia do oprimido, na primavera de 1968, em Santiago do Chile. No entanto, em se considerando a data da primeira edição da obra, em 1970, evidentemente, as comemorações de seu cinquentenário estão se realizando em 2020. Vários exemplos de comemorações poderiam ser aqui listados, mas escapam aos limites deste trabalho. Por isso, elas serão exemplificadas apenas com a iniciativa de publicar um dossiê sobre a efeméride, pela Universidad de La Plata, embora se deva dizer que, por mais fiel que sejam as edições argentinas e as de outras partes do mundo do livro mais conhecido de Paulo Freire, é preciso confrontá-las com a segunda edição de Pedagogia do oprimido: o manuscrito (2018), para que se evidenciem eventuais diferenças resultantes, ou das necessidades de tradução cultural, ou das astúcias ideológicas e de segurança já mencionadas. Desse modo, justificam-se as explicações registradas a seguir, especialmente as da reconstituição histórica da redação do manuscrito e das verdadeiras peripécias que o salvaram da sanha destrutiva dos perseguidores de Freire, bem como dos tortuosos caminhos de suas primeiras edições.

\footnotetext{
${ }^{4}$ Está sobejamente demonstrado que não há tradução linguística, mas tradução cultural e que, na passagem de um idioma para outro, um texto sofre alterações formais para, justamente, atender à manutenção da precisão do sentido original (v. ECO, 2007).
} 
Assim, em 2008, resolvemos fazer uma segunda edição fac-similada do manuscrito de Pedagogia do oprimido ${ }^{5}$, com base nos originais - daí a manutenção da cor azul da caneta usada por Freire e das manchas que as folhas almaço sem pauta ganharam ao longo dos anos - de modo a preservar sua autenticidade, nesta edição, acrescentando-lhe algumas explicações, quer a respeito da própria escritura da obra, que a respeito de suas primeiras publicações.

A busca pela verdadeira origem e trajetória dos originais e das edições de Pedagogia do oprimido pode dar a impressão de ser motivada apenas por uma curiosidade histórica, mas não é. No desvendamento de como se processaram as edições da obra permanece a dúvida, até o presente momento, se todos os editores tiveram acesso a cópias do manuscrito, ou a cópias de uma versão datilografada, ou se se basearam em edições de outros países que haviam mutilado a obra.

\section{COMO PAULO FREIRE CONSTRUÍA UM TEXTO}

O livro Pedagogia do oprimido já passou de 70 edições no Brasil e continua não exibindo o esquema que Paulo Freire desenhou nos manuscritos originais (v. p. 322 e 323 da segunda edição de Pedagogia do oprimido: o manuscrito, de 2018. Por que ainda se publica uma obra mutilada, se os entraves da ditadura militar que impediram a publicação integral dos originais autênticos não existem mais? Esta pergunta ficará melhor esclarecida nas explicações subsequentes.

Em 2001, o Instituto Paulo Freire recebeu uma cópia dos manuscritos deste livro cuja história começa em 1968, quando Paulo Freire os entregou a Jacques Chonchol, diretor do Instituto de Desarrollo Agrario Instituto de Capacitación y Investigación de la Reforma Agrária (ICIRA), onde trabalhava, exilado no Chile.

Quando recebeu Paulo Freire naquele país andino, Jacques Chonchol trabalhava no Instituto de Desarrollo Agropecuario (INDAP), ocupando, depois, a Direção do ICIRA. Sendo uma das principais lideranças do Movimiento de Acción Popular Unitaria (MAPU), Chonchol desgarrou-se do governo socialista-cristão de Eduardo Frei y Montalva, assumiu uma posição

\footnotetext{
${ }^{5}$ A primeira foi publicada em 2013 com base em uma fotocópia do manuscrito e sem a digitação do texto de cada folha do manuscrito na página contígua. Por isso, as páginas manuscritas fac-similadas aparecem em preto (resultantes da fotocópia), quando os originais foram escritos em caneta à tinta azul.
} 
política mais à esquerda do espectro político, tendo sido, inclusive, indicado, pelo movimento, como candidato à presidência do Chile. Com o espírito de estadista que Ihe é peculiar, renunciou à postulação e apoiou a candidatura do então senador Salvador Guillermo Allende Gossens (1908-1973). Segundo explicação do próprio Chonchol aos autores deste artigo, a conjuntura eleitoral seria mais favorável se Allende aceitasse ser o cabeça de chapa do MAPU. A análise de Chonchol estava correta: as esquerdas chilenas chegaram ao poder constituído pela via eleitoral encabeçadas por Salvador Allende. Uma vez eleito, o Presidente Allende convidou Jacques Chonchol para ocupar a pasta do Ministério da Agricultura de seu Governo (1970-1973), mas evidentemente, por sua trajetória política e seu prestígio junto às diversas facções da esquerda chilena, o ministro teria funções políticas muito mais estratégicas do que o mero desempenho na pasta da qual era (e é) um especialista ${ }^{6}$.

Quando Freire saiu do Chile, Chonchol ainda era diretor do ICIRA e, quando ele se tornou ministro de Allende, Freire já estava na Suíça. Ao sair do Chile, Freire dirigiu-se primeiramente para os Estados Unidos, a convite da Universidade de Harvard, onde trabalhou por cerca de onze meses. Estabeleceu-se, em seguida, em Genebra (Suíça), onde permaneceu por uma década, trabalhando no Conselho Mundial de Igrejas (CMI).

Regressou ao Brasil dez anos mais tarde ${ }^{7}$, tendo vivido por mais de uma década e meia no exílio.

Depois de ter doado o manuscrito de Pedagogia do oprimido a Chonchol e à esposa, não mais o viu, pois, no fim da vida, manifestou desejo de revê-lo, ao falar que escreveria a

\footnotetext{
${ }^{6}$ Afortunadamente, ainda vivo em 2019, Jacques Chonchol recebeu um dos autores deste artigo em sua residência em Santiago do Chile e regalou-o com mais uma recente publicação: Por una nueva reforma agraria para Chile (2018).

${ }^{7}$ A lei n.o 6.683, de 28 de agosto de 1976, chamada de Lei da Anistia, resultou diretamente de um projeto de iniciativa do governo de João Figueiredo (1979-1985), o último da ditadura militar implantada pelo golpe de 1964 e que durou por longos vinte e um anos. É evidente, porém, que, embora descaracterizada pela "abertura" lenta e gradual imposta pelos militares - não se estendia aos presos políticos e exilados que haviam cometido "crimes de sangue" e, além disso, perdoava também os torturadores -, o processo de redemocratização do País e com ele a anistia resultaram de amplas mobilizações sociais. De qualquer modo, ela permitiu o retorno dos exilados e, nesse contexto "anistiado", Paulo Freire voltou ao Brasil, em 1980. Ainda assim, teve dificuldade para tirar o passaporte, pois somente o conseguiu depois de várias tentativas nas representações consulares brasileiras em diferentes países e só logrou obtê-lo por meio de um mandato de segurança. Em junho de 1980, aos 57 anos, desembarcou no aeroporto de Viracopos, em Campinas (SP). A anistia mutilada e imposta o impediria ainda de reassumir suas funções docentes na Universidade de Pernambuco. Por isso, fixou residência em São Paulo, aceitando o convite para lecionar na Faculdade de Educação da Unicamp, em Campinas, e, logo depois, ingressou no Programa de Estudos Pós-Graduados em Educação (Supervisão e Currículo) da Pontifícia Universidade de São Paulo (PUC/SP). Contudo, somente 12 anos depois de sua morte, Paulo Freire foi totalmente inocentado, em 26 de novembro de 2009, quando o Estado brasileiro, por meio da Comissão de Anistia do Ministério da Justiça, declarou sua anistia post-mortem, pedindo-lhe, tardiamente, desculpas pelos sofrimentos que Ihe infringira.
} 
Jacques Chonchol para obter uma cópia. Lamentavelmente, faleceu sem rever o documento, uma vez que a cópia obtida, por intermédio do Professor Adriano Salmar Nogueira e Taveira, que foi ao Chile com a missão de consegui-la, chegou ao Brasil depois do falecimento de Freire em 2 de maio de 1997.

Freire dedicou o manuscrito a Jacques Chonchol e à esposa Maria Edy ${ }^{8}$, numa carta escrita e a eles dirigida, com o registro de sua assinatura, do local e da data: "Santiago, primavera de 68". Nesta carta-dedicatória, Paulo Freire fala das saudades que tinha de Recife, após quatro anos de exílio, "de suas pontes, suas ruas de nomes gostosos: Saudade, União, 7 pecados, Rua das Creoulas, do Chora Menino, ruas da Amizade, do Sol, da Aurora". Completava, melancolicamente, ter deixado "o mar de água morna, as praias largas, os coqueiros"; lamenta que deixara "o cheiro da terra e das gentes do trópico, os amigos, as vozes conhecidas". Afirmava ainda que estava deixando o Brasil, mas que, também, "trazia o Brasil" e "chegava sofrendo a ruptura entre o meu projeto e o projeto do meu País". Conclui a carta-dedicatória dizendo: "Gostaria que vocês recebessem estes manuscritos de um livro que pode não prestar, mas que encarna a profunda crença que tenho nos homens, como uma simples homenagem a quem muito admiro e estimo".

Compulsando os originais, percebe-se que Paulo Freire não registrou o título do livro e nem os dos capítulos.

No manuscrito, aparece a epígrafe: "Aos esfarrapados do mundo e aos que neles se descobrem e, assim descobrindo-se, com eles sofrem, mas, sobretudo, com eles lutam". Ela se tornaria o mote da rede de institutos Paulo Freire espalhados pelo mundo.

Cabe acrescentar as explicações que Paulo Freire deu em Pedagogia da esperança: um reencontro com a Pedagogia do oprimido (1992) sobre a elaboração e o processo de edição da obra, em mais de um país, concluindo com informações preciosas sobre a negociação da edição de Pedagogia do oprimido no Brasil. Primeiramente, ele informa que o "processo de redação" foi debatido com vários intelectuais, especialmente com os chilenos e brasileiros exilados naquele país, afirmando textualmente:

\footnotetext{
${ }^{8}$ Maria Edy era brasileira de Limeira, interior do estado de São Paulo, e Chonchol a conhecera, no Brasil, por ocasião do 4. o centenário da cidade de São Paulo, segundo informação do próprio ex-ministro de Allende, em entrevista concedida a um dos autores deste trabalho.
} 
Foi vivendo a intensidade da experiência da sociedade chilena, da minha experiência naquela experiência, que me fazia re-pensar sempre a experiência brasileira, cuja memória viva trouxera comigo para o exílio, que escrevi a Pedagogia do oprimido entre 1967 e 1968 (FREIRE, 1994, p. 53).

Em seguida, explica o próprio método de escrita, desse e de outros textos de sua autoria, segundo o qual, antes de registrá-las, as ideias são por ele submetidas, exaustivamente, ao debate e à discussão:

O tempo de escrever, diga-se, ainda é sempre precedido pelo de falar das ideias que serão fixadas no papel. Pelo menos foi assim que se deu comigo. Falar delas antes de sobre elas escrever, em conversas de amigos, em seminários, em conferências, foi também uma forma de não só testá-las, mas de recriá-las, de repartejá-las, cujas arestas poderiam ser melhor aparadas quando o pensamento ganhasse forma escrita com outra disciplina, com outra sistemática.

[...] Levei mais de um ano falando de aspectos da Pedagogia do oprimido. Falei a amigos que me visitavam, discuti-os em seminários, em cursos. Um dia, minha filha Madalena chegou a chamar, delicadamente, minha atenção para o fato. Sugeriu maior contenção de minha parte na ânsia de falar sobre a Pedagogia do oprimido ainda não escrita. Não tive forças para viver a sugestão. Continuei apaixonadamente falando do livro como se estivesse, e na verdade, estava aprendendo a escrevê-lo (FREIRE, 1994, p. 54).

Todo o processo de criação do livro foi desenvolvido aos poucos, em discussões com pessoas que encontrava.

Cabe, aqui, um parêntese teórico e que diz respeito ao sujeito da criação cultural. Para os freirianos, este sujeito é mais do que coletivo; é transindividual. Para se entender esta diferença, há de se recorrer ao exemplo anedótico oferecido por Lucien Goldmann (1972): Imagine-se que uma pessoa queira levantar um piano de cauda muito pesado. Aplica toda sua força em um ponto do instrumento e não consegue levantá-lo, evidentemente. Apela para mais pessoas que, somando suas forças à do levantador originário, não logram, tampouco, levantar a peça, enquanto aplicam o montante das forças no mesmo ponto do piano. Só têm sucesso, quando somam as forças e as aplicam em pontos diferentes do objeto a ser levantado. Portanto, enquanto o sujeito coletivo seria o resultante do mero somatório das forças dos sujeitos individuais, o sujeito transindividual é a soma das capacidades dos indivíduos, mas lhe acrescenta uma qualidade nova, constituindo um novo sujeito: a aplicação das forças individuais em diferentes pontos do objeto a ser levantado. Nesta perspectiva, os(as) grandes artistas, pensadores(as) e cientistas não seriam, no limite, os autores de suas 
obras geniais, mas os "formatadores" de obras já criadas, coletiva e transindividualmente. É claro que sua marca pessoal está no estilo, na forma, na síntese de sucesso obtida pelo "autor" individual, que tem a capacidade de perceber a potencialidade da criação social, dando-lhe uma forma adequada e historicamente oportuna. Foi o que, certamente, fez Paulo Freire, no processo de escritura de Pedagogia do oprimido.

Ainda exilado no Chile, recorria também às fontes secundárias dos autores que the inspiravam, sempre anotando, em pedaços de papel, o que lhe ocorria, numa espécie de verdadeiro "alvoroço intelectual" (FREIRE, 1994, p. 54). Combinava tais anotações com os registros que fizera em fichas, nas experiências e nos círculos de cultura de que participara em comunidades camponesas chilenas. Lançava mão, também, das lembranças de experiências que tivera no Nordeste brasileiro, antes do exílio. Em suma, como afirma e reafirma o próprio Freire, buscava combinar as contribuições dos intelectuais com o "saber de experiência feito" (FREIRE, 1994, p. 59), do senso comum dos educandos e demais participantes dos círculos de cultura. Complementa que, as "fichas de ideias" acabavam por se tornar verdadeiras "fichas geradoras", num trabalho artesanal que, certamente, demandaria um esforço de arranjo e organização que deve ter-Ihe tomado muito tempo e energia. Freire informa que, com essa metodologia de escritura, em 15 dias, atravessando noites, escreveu os três primeiros capítulos da obra, em julho de 1967 (FREIRE, 1994, p. 60).

Assim que concluiu a primeira versão do trabalho, com apenas três capítulos, entregou os originais datilografados a Ernani Maria Fiori ${ }^{9}$, para que escrevesse o prefácio. Recebendo de volta a obra prefaciada por Fiori, Freire informa: "Quando Fiori me entregou seu excelente estudo em dezembro de 1967, tomei algumas horas em casa à noite, lendo desde o seu prefácio até a última palavra do terceiro capítulo, para mim, então, o último" (FREIRE, 1994, p. 60). Embora o livro estivesse pronto para publicação, Freire resolveu seguir o conselho do

\footnotetext{
${ }^{9}$ Ernani Maria Fiori (1914-1985) bacharelou-se pela Faculdade de Direito de Porto Alegre, em 1935. Catedrático de História da Filosofia na Faculdade de Filosofia da Universidade Federal do Rio Grande do Sul (UFRGS). Como Paulo Freire, exilou-se no Chile por causa do golpe de 1964 no Brasil, atuando na Universidade Católica, da qual chegou a ser vice-reitor. Foi reintegrado à UFRGS, em 1979.
} 
amigo Josué de Castro ${ }^{10}$ que, segundo ele, estivera no Chile e que, em conversa com ele e cm outro grande amigo, também exilado, Almino Affonso ${ }^{11}$, numa das praças de Santiago, aconselhara-o a guardar o texto por três ou quatro meses e, depois, voltar a ele, relê-lo e, só então, tomar a decisão de publicá-lo, ou na forma em que o encontrasse, ou acrescentando partes, já que este modo de concluir uma obra poderia levá-lo a fazer as alterações que considerasse definitivas. Embora tentado a rever o texto em "quarentena" por várias vezes, Freire informa ter resistido à tentação, para dele alcançar algum "distanciamento":

Lá uma noite dois meses e pouco depois, me entreguei por horas ao reencontro com os originais Era quase como se tivesse reencontrando um velho amigo. Foi mesmo com emoção grande que li, lentamente, sem querer mesmo que a leitura terminasse logo, página por página, o texto todo. [...] Não realizei mudanças importantes nele, mas fiz a fundamental descoberta de que o texto estava inacabado. Precisava de um capítulo a mais. Foi assim, então, que escrevi o quarto e último capítulo [...] (FREIRE, 1994, p. 60-61).

Não satisfeito com todo esse cuidado com a revisão da primeira versão, Freire ainda prolongou o processo de discussão dos originais, antes de entregá-los aos editores norteamericano e uruguaio:

Terminada finalmente a redação do quarto capítulo, revistos e retocados os três primeiros, entreguei o texto todo a uma datilógrafa para que o batesse à máquina. Em seguida, fiz várias cópias que distribuí entre amigos chilenos e alguns companheiros de exílio e amigos brasileiros (FREIRE, 1994, p. 62).

São necessários dois destaques para o bem da verdade a respeito das matrizes que foram oferecidas aos editores para publicação. Em primeiro lugar, Freire diz ter tirado várias cópias do texto que completara com um quarto capítulo e com o "retoque" dos demais, entregando-o, em seguida a "uma datilógrafa para que o batesse à máquina" (id., ibid.).

10 Josué Apolônio de Castro (1908-1973), médico, geógrafo e cientista social, destacou-se, nacional e internacionalmente, por seus estudos sobre a fome. Escreveu várias obras, dentre as quais se destaca Geografia da fome (1961). Foi presidente do Conselho Executivo da Organização das Nações Unidas para Agricultura e Alimentação (FAO) e embaixador brasileiro junto à ONU. Quatro vezes indicado ao Prêmio Nobel da Paz (1953, 1963, 1964 e 1965). Do mesmo modo que Paulo Freire (7a. edição), foi um dos biografados do Projeto Memória (6a. edição) do Banco do Brasil. O Projeto Memória tem por finalidade "difundir a obra de personalidades que contribuíram significativamente para a transformação social, a formação da identidade cultural brasileira e o desenvolvimento do Brasil". Disponível em: <http://www.projetomemoria.art.br/>. Acesso em: 19 maio 2018. Está na sua 13a. edição, tendo homenageado, pela ordem, Castro Alves, Monteiro Lobato, Rui Barbosa, Pedro Álvares Cabral, Juscelino Kubitschek de Oliveira, Oswaldo Cruz, Josué de Castro, Paulo Freire, Nísia Floresta, João Cândido, Marechal Rondon, Carlos Drummond de Andrade e Lélia Gonzalez.

${ }^{11}$ Almino Monteiro Álvares Affonso, advogado, foi ministro do trabalho do governo de João Goulart, deposto pelo golpe militar de 1964 e, por isso, também exilado em vários países (Argentina, lugoslávia, Peru, Uruguai), inclusive no Chile, onde conviveu com Paulo Freire. Foi deputado federal por mais de um mandato e ocupou cargos nos governos do estado de São Paulo, chegando a ser vice-governador. 
No entanto, por duas vezes, um dos autores deste artigo conversou com Clodomir de Morais, lamentavelmente já falecido, que lhe garantiu ter datilografado o livro para o amigo Paulo Freire. Portanto, a crer nesta versão, Freire teria entregue o texto a um "datilógrafo" e, não, a uma "datilógrafa". Em segundo lugar, Freire afirma ter tirado várias cópias certamente fotocópias - "que distribuiu entre amigos chilenos e companheiros de exílio e amigos brasileiros" (id., ibid.). Ora, ele não menciona a entrega de qualquer cópia a editores, para a publicação do texto. Desse modo, permanece a indagação: Ao contratar a publicação de Pedagogia do oprimido com qualquer editora, sob que forma Freire entregara os originais? Fotocópias do texto datilografado, seja por quem for, ou cópias do manuscrito? A hipótese que mais se nos evidencia é a de que o manuscrito é que foi copiado de uma das cópias datilografadas, dado o capricho com que foi feito - é uma verdadeira "diagramação à mão" (!) de quem estava imbuído pela intenção de presentear o futuro ministro e esposa com uma versão caprichada do texto.

Depois de rever a forma com que Paulo Freire criava seus textos - longo processo de "gestação", como ele mesmo o chamava, por meio de sua submissão à leitura de outrem, especialmente de Elza, "uma ouvinte atenciosa e crítica, [...] minha primeira leitora, igualmente crítica" (FREIRE, 1994, p. 65) -, é necessário reconstituir a história do processo de edição da obra e sua relação com o manuscrito que ora se dá à luz, por meio da 2ạ. edição de Pedagogia do oprimido: o manuscrito (2018), totalmente patrocinada pela Universidade Nove de Julho, de São Paulo, Brasil.

\section{AS EDIÇÕES DA OBRA}

A partir da primeira edição, que tanto pode ser a norte-americana (Herder \& Herder, 1970) ${ }^{12}$, quanto a que surgiu no Uruguai, em espanhol (Tierra Nueva, 1970), seguiram-se a italiana (Arnoldo Mondadori, 1971), a alemã (Kreuz-Verlag, 1971) e a francesa (Maspero,

\footnotetext{
12 Em recente visita ao Brasil, o estudante de mestrado em Ciências da Educação, Carlos Federico Brugaletta informou que obteve cópia da carta que Paulo Freire enviou ao editor uruguaio da época. Pela carta fica muito forte a hipótese de que Pedagogia do oprimido tenha sido publicado pela primeira vez em espanhol, no Uruguai, nos termos que o próprio Paulo Freire explica em Pedagogia da Esperança. Carlos F. Brugaletta é Professor de Ciências da Educação na Universidad Nacional de la Plata e arquivista (ISEDDyT n.o 8), estudante de Mestrado em Historia e Memoria e do Doutorado em Ciências da Educação da Faculdade de Humanidades e Ciências da Educação, onde desenvolve tese sobre as relação de Paulo Freire e as editoras católicas. É bolsista do CONICET. É, também, ajudante diplomado em História da Educação Geral e membro da Sociedade Argentina de História da Educação.
} 
1974), como explica o próprio Paulo Freire, que devia ter as datas de publicação bem claras, na época em que concluiu Pedagogia da esperança: um reencontro com a Pedagogia do oprimido (1992). Nesta mesma obra, explica que a publicação em português (Paz e Terra, 1975), no Brasil, somente se deu depois da francesa. Desse modo, a brasileira não foi a primeira na língua materna de Freire. Se ela veio depois da francesa e a primeira edição em Portugal, pela editora Afrontamento, ocorreu em 1972, a brasileira deve ter sido a sétima.

Os primeiros editores de Pedagogia do oprimido devem ter recebido cópias da versão datilografada, como explica Freire na obra mencionada no parágrafo anterior. Como entender, então, a existência de um manuscrito? Teria sido ele a base para a versão datilografada e desta teriam sido extraídas as cópias enviadas aos editores pelo próprio Paulo Freire? Ele se refere apenas a uma versão datilografada, "batida à máquina", como registra em Pedagogia da esperança (FREIRE, 1994, p. 62-63).

Certamente as posteriores edições da obra, nos diversos idiomas dos muitos países do mundo basearam-se na versão uruguaia, em castelhano, ou na versão norte-americana, em inglês, ou, simultaneamente, em ambas. De fato, embora tivesse escrito a obra no Chile e dominasse bem o espanhol falado naquele país, escreveu-a em português. Ora, o idioma materno de Freire não tem a expressão fora dos poucos países de fala lusófona como têm essas verdadeiras "línguas francas" (castelhano e inglês), pelo menos no mundo ocidental.

As edições posteriores às sete primeiras certamente foram baseadas em tradução da tradução - a brasileira foi a sétima e ela também se realizou a partir de uma cópia (datilografada) enviada, clandestinamente, para o editor Fernando Gasparian. e cujas peripécias para passar na alfândega brasileira o próprio Freire descreveu tão bem na obra já mencionada. A edição brasileira não traz os dois diagramas mencionados, um ao lado do outro, que têm por título, respectivamente, "Teoria da Ação Revolucionária" e "Teoria da Ação Opressora" (p. 15 do capítulo IV e à p. 322-323 do manuscrito fac-similado). Assim, ela não foi matriz das edições em que eles aparecem.

A edição alemã, ou se baseou na cópia datilografada enviada por Freire, ou surgiu a partir da na norte-americana, pois ambas trazem os diagramas, respectivamente, às páginas 131 e 114.

A edição francesa não contém os desenhos de Freire, nem na última, realizada em 2018, com base na norte-americana e na brasileira. 
A primeira edição portuguesa traz os diagramas de Freire (v. p. 188). A segunda edição realizada em terras lusas, em 2018, não traz os diagramas, porque, segundo informação pessoal do editor da Afrontamento aos autores deste artigo, os direitos autorais para a língua portuguesa são da editora brasileira - que não traz os desenhos originais de Freire pelas razões que serão explicadas mais adiante - e, por isso, teve de se basear na da última edição brasileira.

Mesmo a partir da 17a. edição brasileira, Pedagogia do oprimido ainda não traria os dois diagramas mencionados nas edições brasileiras subsequentes. E por que se destaca, neste texto, a 17a. edição brasileira da obra? Sobre esta edição vale a pena uma pequena explicação: um exemplar da 15a. edição da obra no Brasil foi encontrado numa das prateleiras do Instituto Paulo Freire, todo revisado à mão, pelo próprio Paulo Freire. Providencialmente quem a encontrou tirou imediatamente uma fotocópia, porque, lamentavelmente essa revisão original se perdeu. Certamente, com base nessa revisão do próprio autor, nasceu a 17a. edição, "a primeira decente", teria dito Paulo Freire, numa dedicatória de um exemplar que ofereceu a Moacir Gadotti e a sua esposa Rejane.

O próprio Paulo Freire reconheceu a importância do aprendizado que teve no Chile, seja a partir da vivência no contexto pré-revolucionário, seja pela inspiração dos autores socialistas a que teve acesso. Por isso, dentre outras razões, justifica-se a publicação simultânea do manuscrito com a transcrição em espanhol, que se realizou no Chile, pelo Programa Interdiciplinario de Investigaciones em Educación (PIIE), em articulação com o Ministério da Educação daquele país andino e com a editora da Universidade Nove de Julho, do Brasil, em 2018.

Segundo o depoimento do próprio autor, antes de ser publicado em português, Pedagogia do oprimido foi publicado em inglês, espanhol, italiano, francês e alemão (FREIRE, $1994)^{13}$.

Tentando driblar a vigilância da ditadura militar e sabendo que o livro não poderia ser publicado no Brasil, Paulo Freire informa que enviou uma cópia datilografada ao diretor da Editora Paz e Terra, Fernando Gasparian (FREIRE, 1994). O portador dos originais para o Brasil foi o professor da Universidade de Genebra e conselheiro nacional da Suíça, Jean Ziegler, que

\footnotetext{
${ }^{13}$ Freire certamente se esqueceu da edição portuguesa, que foi negociada pessoalmente com ele, em Genebra, segundo o editor da Afrontamento, também em informação pessoal aos autores deste artigo.
} 
não foi incomodado pelas autoridades alfandegárias nacionais, certamente por causa de seu passaporte diplomático.

Vamos dar novamente a palavra ao próprio Paulo Freire pela importância da informação:

Dias depois, Gasparian discretamente, acusava o recebimento do material pedindo que esperasse por tempos mais favoráveis por sua publicação ${ }^{14}$. Remeti o texto nos fins de 1970, quando o livro já tinha sua primeira edição em inglês, nos começos de 1971. Sua publicação aqui, sua primeira impressão só foi possível em 1975 (FREIRE, 1994, p. 63).

Ora, considerando as datas das aquisições dos direitos autorais da obra para as publicações em outros países, a do Brasil, de 1975, segundo Paulo Freire, deve ter sido a sétima edição da obra, antecedida, pela ordem, pela do Uruguai (1970), dos Estados Unidos (1970), da Alemanha e da Itália (ambas no ano de 1971), de Portugal (1972) e, finalmente, pela da França (1974).

Um pouco mais adiante, Freire comenta que um grupo de operários Ihe escrevera uma carta na qual comentavam que haviam estudado a obra, em português, a partir de "uma cópia do original batido à máquina no Chile" (FREIRE, 1994, p. 63). Esta informação de Freire demonstra que, apesar da proibição, a obra era lida no Brasil clandestinamente, a partir de cópias do original datilografado, ou em edições estrangeiras, como narra também Freire, o caso da freira que "no regresso de suas viagens aos Estados Unidos, com alguns exemplares da Pedagogia, sobre cuja capa original ela punha capas de livros religiosos" (FREIRE, 1994, p. 63).

Por toda essa trajetória da redação de Pedagogia do oprimido e de suas primeiras edições, pode ser que o manuscrito foi escrito antes, servindo de base para a versão datilografada. Como pode ter sido escrito depois, com base na versão datilografada, dado o capricho com que que foi manuscrito - verdadeiramente "diagramado à mão, como já foi afirmado neste texto - e, neste caso, confirmando a hipótese dos autores deste artigo sobre a precedência da versão datilografada e suas cópias.

\footnotetext{
${ }^{14}$ Teria sido pelos fatores de "tempos menos favoráveis" que Gasparian teria eliminado os diagramas sobre a "teoria da ação revolucionária" e "teoria da ação opressora", que tanto chamavam a atenção nos originais, das edições da obra no Brasil? O que não se justifica mais é manter tal mutilação nas edições contemporâneas que se dão no Estado de Direito.
} 
A data da dedicatória do manuscrito a Jacques Chonchol e a Maria Edy, a esposa do ex-ministro de Allende - "Paulo, Santiago, Primavera 68" o indicam. E, naquela oportunidade, o livro já estava acrescido do quarto capítulo.

O prefácio de Ernani Maria Fiori, datado de dezembro de 1967, "excelente estudo", se refere ao livro "inacabado", como disse o próprio Paulo Freire (FREIRE, 1994, p. 61), com apenas três capítulos. O prefácio não aparece em algumas edições realizadas em outros países, como, por exemplo, na primeira, realizada nos Estados Unidos. Nela, as "Primeiras Palavras", de autoria do próprio Paulo Freire, viraram "preface", antecedido por um "foreword" (que também quer dizer prefácio) de Richard Shaull. A edição italiana de 2011 (Edizione Grupo Abele) também eliminou o prefácio de Fiori, substituindo-o pelo de autoria de Silvia Maria Manfredi e Piergiorgio Reggio, embora tenha figurado na primeira edição italiana de Arnoldo Mondadori.

Mesmo com toda essa gênese transindividual de produção de uma obra e de sua tumultuada trajetória editorial no Brasil - fruto de uma ditadura militar regressiva que estabeleceu uma dura censura a quem com ela não concordava -, Paulo Freire é o responsável por essa síntese do pensamento progressista de uma época, constituindo-se como um verdadeiro intelectual orgânico dos oprimidos e oprimidas e apontando, consciente e intencionalmente, para um processo revolucionário por meio de uma educação como único caminho para que a humanidade não caia na barbárie e construa um mundo onde ainda seja possível amar.

Quando a contrarrevolução explodiu no Chile e as tropas de Pinochet atacaram o palácio do governo e mataram o Presidente Salvador Allende, Jacques Chonchol, seu principal ministro também sofreria sérias represálias. Escapou com vida porque estava em missão no exterior, voltando ao Chile no dia do golpe e fugindo graças à ajuda de amigos. Tendo a casa invadida e sua biblioteca confiscada, o manuscrito escapou porque, certamente os esbirros da ditadura que se implantava naquele país andino não deram muita importância para uma pasta simples de cartolina, contendo folhas de papel almaço escrita à mão.

Por mais de quatro décadas, o manuscrito permaneceu em poder da família Chonchol, tendo sido levado para Paris, pela irmã do ex-ministro exilado. Como ele narra na entrevista contida na edição do manuscrito, por um triz não o entregou a um órgão da Unesco instalado na capital francesa. Ao retornar a Santiago, levou de volta o manuscrito e guardou-o cuidadosamente. 
Finalmente, por um ato de generosidade extrema, mas com o espírito de estadista que o caracteriza, tomou a decisão de doá-lo ao povo brasileiro e, de fato, entregou o manuscrito de Pedagogia do oprimido, em uma belíssima cerimônia realizada na Universidade Nove de Julho de São Paulo, em 5 de novembro de 2013.

\section{A ATUALIDADE DE PEDAGOGIA DO OPRIMIDO E DO LEGADO DE PAULO FREIRE}

O apelo reiterado de Paulo Freire em vida por si só perpetuaria a atualidade de sua obra e de seu legado: "Não me repitam; reinventem as ideias em cada contexto". Ora, não há nada mais atual em qualquer teoria do que o reiterado apelo de seu próprio autor para sua constante atualização. Além disso, as pesquisas insuspeitas realizadas fora do Brasil que colocam o livro Pedagogia do oprimido como um dos mais traduzidos, mais demandados e mais lidos no mundo, ratificam essa atualidade.

Passado um século de seu nascimento, se ainda vivo, Paulo Freire não teria a exata dimensão da repercussão de sua obra por todo o Planeta. Foi assim sua reação de espanto, quando, em 1996, Moacir Gadotti e José Eustáquio Romão foram à sua residência, situada na Rusa, n. 170, no Bairro Alto do Sumaré, em São Paulo, Brasil, entregar-lhe o primeiro exemplar de Paulo Freire: uma biobibliografia que acabara de sair. Esta publicação resultara de um esforço conjunto de membros do Instituto Paulo Freire do Brasil de levantar, até aquela data tudo que saíra no mundo a respeito do autor de Pedagogia do oprimido. Certamente a atualização desta obra, numa tentativa de produzir uma espécie de vade-mecum sobre Paulo Freire geraria, hoje, em 2020, mais de um volume da mesma dimensão (mais de 700 páginas). Em outras palavras, passados quase 25 anos da primeira tentativas de levantar o "estado da arte" do legado freiriano, as repercussões e as produções sobre o educador pernambucano ampliaram-se exponencialmente, numa prova incontestável de sua atualidade e importância no mundo.

Em 2020, vários eventos estão já ocorrendo em várias partes do Brasil e do mundo, no sentido da comemoração do centenário de nascimento de Freire. A pandemia do Corona Vírus acabou provocando uma providencial alteração no calendário do principal acontecimento da comunidade freiriana mundial: o tradicional Encontro Internacional do Fórum Paulo Freire, que se realiza bienalmente, nos anos pares e que congrega freirianos de todo o Planeta, foi adiado de setembro de 2020 para setembro de 2021, a realizar-se em Paris, no ano do 
centenário de Paulo Freire. Para a capital francesa deverão convergir os olhos do mundo, especialmente os dos educadores, no sentido de aquilatar que ecos do legado freiriano poderão orientar o mundo na revisão seus procedimentos educacionais e de seus protocolos de convivência humana na pós-pandemia.

\section{REFERÊNCIAS}

CHONCHOL CHAITT, Jacques. Por uma nueva reforma agraria para Chile. Santiago: LOM, 2018.

ECO, Umberto. Quase a mesma coisa: experiências de tradução. Tradução Eliana Aguiar, São Paulo: Record, 2007.

FREIRE, Paulo. Pedagogía del oprimido. Montevideo: Tierra Nueva, 1970.

FREIRE, Paulo. Pedagogy of the oppressed. New York: Herder \& Herder, 1970.

FREIRE, Paulo. Pädagogik der Unterdrückten. Stuttgart: Kreuz-Verlag, 1971.

FREIRE, Paulo. La pedagogia degli oppressi. Milano: Mondadori, 1971.

FREIRE, Paulo. Pedagogia do oprimido. Porto: Afrontamento, 1972.

FREIRE, Paulo. Pédagogie des opprimés. Paris: Maspero, 1974.

FREIRE, Paulo. Pedagogia do oprimido. Rio de Janeiro: Paz e Terra, 1975.

FREIRE, Paulo. Pedagogía del oprimido. Traducción Programa Interdisciplinario de Investigaciones en Educación, Santiago: Ediciones Universidad Tecnológica Metropolitana, 2018.

FREIRE, Paulo. Pedagogia do oprimido: o manuscrito. São Paulo: Ed,L; Ed. Uninove; BT Acadêmica, 2018 (Projeto Editorial, Organização, Revisão e Notas Jason Ferreira Mafra, José Eustáquio Romão e Moacir Gadotti).

FREIRE, Paulo. Pedagogia da esperança: um reencontro com a Pedagogia do oprimido. 3. ed. Rio de Janeiro: Paz e Terra, 1994.

GADOTTI, Moacir. Paulo Freire: uma biobibliografia. São Paulo: Cortez, Instituto Paulo Freire; Brasília: UNESCO, 1996.

GOLDMMANN, Lucien. A criação cultural na sociedade moderna. Tradução Rolando Roque da Silva, 3. ed. São Paulo: DIFEL, 1972. 
MC LAREN, Peter. Che Guevara, Paulo Freire y la pedagogía de la revolución. Tradução María Guadalupe Benítez Toriello, México: Siglo XXI, 2001.

Recebido em 28 de janeiro de 2020.

Aprovado em 03 de abril de 2020

(c) 